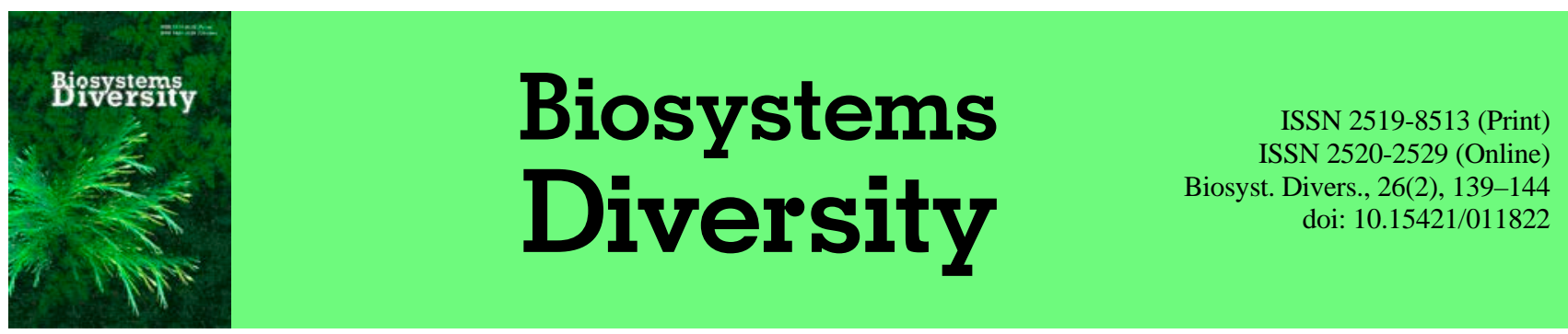

\title{
The effect of vortex structures in the river bed on the concentration and size differentiation of the fish population
}

\author{
A. A. Chemagin \\ Tobolsk Complex Scientific Station UD RAS, Tobolsk, Russia
}

Article info

Received 19.04.2018

Received in revised form 07.05.2018

Accepted 10.05.2018

Tobolsk Complex Scientific Station UB RAS,

Ac. Yuri Osipov st., 15 ,

Tobolsk, 626152, Russia

Tel.: +7-982-923-99-40

E-mail:

ChemaginAA@yandex.ru

\begin{abstract}
Chemagin, A. A. (2018). The effect of vortex structures in the river bed on concentration and size differentiation of the fish population. Biosystems Diversity, 26(2), 139-144. doi:10.15421/011822

On the basis of recent hydroacoustic method with using "PanCor" computerized program-technological complex, research was conducted on the distribution of fish of different taxonomic groups in the water area of Irtysh, a large transborder river on the bend (meander) with a vortex zone. A hydroacoustic complex allows one to conduct remote sizetaxonomic identification of fish. It is demonstrated that on the examined area of the river, fish of different taxonomic groups and sizes concentrate in the zones of increased turbidity and intense whirlpools (vortices) which form as a result of opposite currents at the river meander. The largest concentrations of fish form in the deepest zone of the examined water area and in front of it - vortex zone. It was determined that in the zone of recorded vortices, the number of fish of different taxonomic groups (Cyprinidae, Percidae, Coregonidae, Esocidae, Acipenseridae, Lotidae) is on average 2.14-2.61 times reliably higher compared to the observations at the studied part of the river with no vortices at comparable parameters of depth. The size structure of the fish was dominated by small individuals $(<10 \mathrm{~cm})$ in the vortices, and large fish out of these zones, which can be an additional element of the survival strategy. The peculiarities of the studied area of the river with vortices, on one hand, are the factors of formation of fish concentrations, and on the other hand - factors of differentiation by taxonomical and size parameter, related to inability of certain groups of organisms to resist the hydrodynamic force of the vortex structure.
\end{abstract}

Keywords: hydroacoustic survey; fish behaviour; concentrations of fish; defensive behaviour; size differentiation of fish; turbulence

\section{Introduction}

Many hydrobionts, including fish, chose a certain intensity and orientation of different ecological factors as optimum conditions for somatic growth (Altenritter et al., 2013), feeding (Nakayama et al., 2018), and shelter from predators (Muška et al., 2013). Rapid fluctuations of currents of water masses and transition of particles into the water column form a hydrodynamic and optimum non-uniformity of the environment preferred by many hydrobionts which use this effect as a "window of anti-predation” (Hansen \& Beauchamp, 2015). Meanders, sharp bends in the stream beds of rivers, cause a complex of phenomena in the deep parts of rivers - whirlpools (vortices) (Velikanov, 1958; Baryshnikov, 2007) formed due to turbulent circulations of water masses (Ovsyanik, 2016; Verin, 2017) and clouds of increased turbidity (clouds of effervescence), the formation of which is the result of large scale vortex structures. In the lower current of the trans-border river Irtysh, there is a number of such areas which are called "riverbed depressions". The largest of them are the Kondinskaya and Gornoslinkinskaya riverbed depressions located in the subarctic zone of Western Siberia (Russian Federation). Therefore, the objective of this study was to determine the size-taxonomic peculiarities of distribution of fish in the water areas of the Kondiskaya riverbed depression within and outside vortexes.

\section{Materials and methods}

The studies were conducted on a stretch of the Irtysh, 90-95 km (May 2016) in the coordinates 60²'28,21"N, 6940'34.88"E. The deepest point was more than $40 \mathrm{~m}$, and the width of the stream bed in that period exceeded $500 \mathrm{~m}$. The studied water area covered over 117 ha. The assessment of the size sequence, number and distribution of fish in the water column of the studied water area of the riverbed depression was made using PanCor (Promhydroacoustics LLC, Petrozavodsk) hydroacoustic program-technical complex. The work of the complex is based on the vertical monitoring with double ray with 200 and $50 \mathrm{kHz}$ frequency. During the study, a small vessel moved within the borders of the studied river plot according to the tack coordinates and generally accepted methods (Yudanov et al., 1984), at the same time, conducting the hydroacoustic sounding. The obtained records were processed in the laboratory conditions in PanCor and Taxonomy special program additions. The algorithm of the hydroacoustic data processing is based on remote taxonomic identification of fish at the level of families by form of the reflected sound, which is affected by the form of the swim bladder - Cyprinidae, Percidae, Coregonidae-Esocidae, undetermined (Acipenseridae, Lotidae) (Borisenko et al., 2006, Mochek et al., 2015). Charts of fish distribution and visualization of the bed relief were developed in Surfer 9.0 program using interpolation method of Kriging and 3D Surface respectively. Before developing the charts, the map was the calibrated in Mapviewer 6.0, the screen shot of the area with calibration points with known geographic coordinates was imported from Google Earth Pro. The statistical analysis of the data was made using Statistica 10.0 (Statsoft Inc., USA).

The study of the species composition of the fish population was made using the method of the control catching through gill netting and drift netting (the size of a cell was 14, 25, 35, 45, 55, $65 \mathrm{~mm}$, the net length was 35-75 m). For achieving the goals of the study, the following tasks were set: study the horizontal distribution and size structure of fish, average number of recorded fish which belong to different families: Cyprinidae, Percidae, Coregonidae-Esocidae, and groups of undetermined fish (Acipenseridae, Lotidae) in the water area of the riverbed depression within and out of the zone of whirlpools (vortices), determine the places of highest fish concentration by developing the charts of horizontal distribution of the fish. 


\section{Results}

The studied area of the river is located at a sharp bend of the Irtysh stream bed at $<90^{\circ}$ angle, the left-bank tributary - the Konda river - causes additional inflow and hydrodynamic disturbance (Fig. 1).
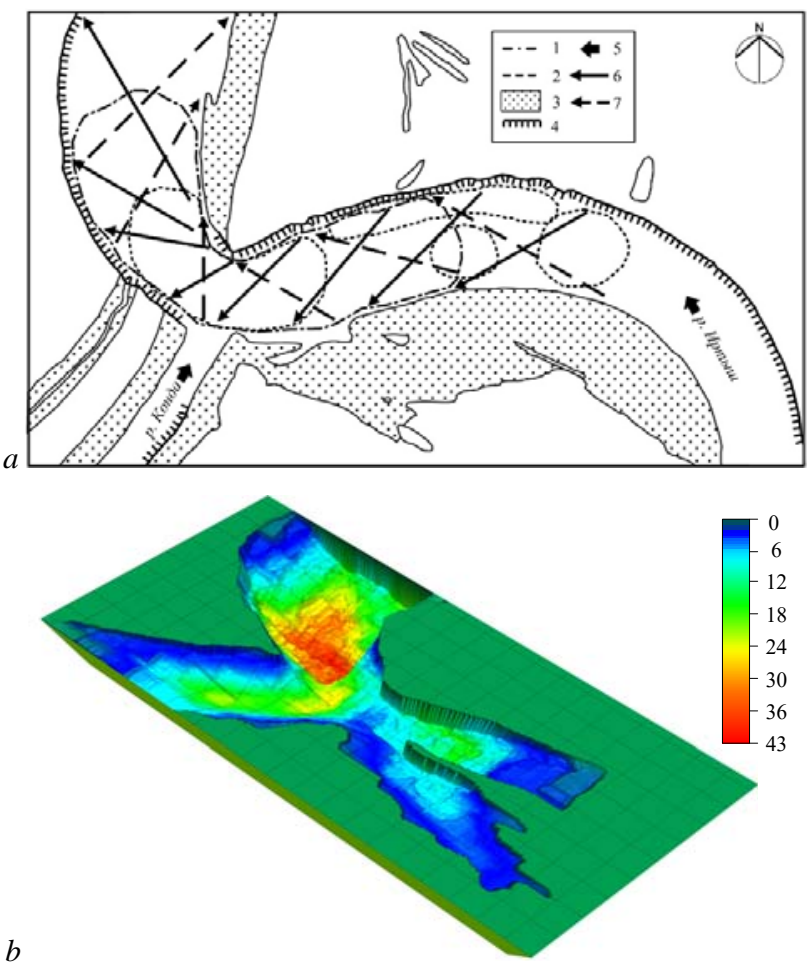

Fig. 1. Schematic map of Kondinskaya winter riverbed depression, in the studied stretch of the Irtysh, its hydrogeological peculiarities (a) and 3D-visualization of the bed relief $(b)$ of the Kondinskaya riverbed depression: 1 - water area of the lotic part of the riverbed depression; 2 - the zone of visual determination of vortices and ascending currents with weighed particles (cloud of effervescence); 3 - the flooded plains in the period of high water level; 4 - shores washed out as a result of stream bed processes; 5 - the direction of current; 6 - direction of surface current jets; 7 - the direction of the surface current jets (* - according to N. B. Baryshnikov (2007))

It was demonstrated (Baryshnikov, 2007; Blanckaert et al., 2013; Vermeulen et al., 2014) that at the curve values of meander higher than critical values, surface and pre-bed natural cross-cut circulations (currents) and whirlpool zone (area of visually recorded vortices) form at the internal shore behind the central section. In the central part of the studied water area, several zones of excessive turbidity and vortices were observed, the largest was in the central and deep part of the riverbed depression and directly in front of it (Fig. 1).

The floodplain-stream bed system of the Irtysh is an important conponent of the Ob-Irtysh basin with large fish resources. According to the control catching in the area of our studies, the fish population is represented by typical species for the Lower Irtysh: sterlet (Acipenser ruthenus Linnaeus, 1758), Siberian sturgeon (A. baerii Brandt), nelma (Stenodus leucichthys nelma Pallas, 1773), roach (Rutilus rutilus Linnaeus, 1758), ide (Leuciscus idus Linnaeus, 1758), Eurasian dace (Leuciscus leuciscus Linnaeus, 1758), bream (Abramis brama Linnaeus, 1758), gold crucian (Carassius carassius Linnaeus, 1758), silver crucian (C. auratus Linnaeus, 1758), European perch (Perca fluviatilis Linnaeus, 1758), Eurasian ruffe (Gimnocephalus cernuus Linnaeus, 1758), zander (Sander lucioperca Linnaeus, 1758), northern pike (Esox lucius Linnaeus, 1758), burbot (Lota lota Linnaeus, 1758). All specimens caught of the Siberian sturgeon were immediately released into the natural environment with the least possible harm. As a result of remote echometric sounding, it was determined that the main part of the fish population in the studied plot of the watercourse is represented by Cyprinidae both in the zone of vortices, and out of this zone $-67.3 \%$ and $66.9 \%$, the share of Percidae $-23.6 \%$ and $23.1 \%$, Coregonidae - Esocidae $-4.9 \%$ and $5.8 \%$, unidentified (Acipenseridae, burbots) $-4.2 \%$ and $4.1 \%$ of the corresponding total of recorded fish (Table).

\section{Table 1}

The average number of individuals and percentage ratio of the recorded groups of fish by points of registration in the zone of vortices and out of this zone*

\begin{tabular}{|c|c|c|c|c|c|c|}
\hline \multirow{2}{*}{$\begin{array}{l}\text { Plots of the } \\
\text { water area of } \\
\text { the riverbed } \\
\text { depression }\end{array}$} & \multirow{2}{*}{ Depth, m } & \multicolumn{4}{|c|}{$\begin{array}{l}\text { Number of the recorded fish by groups, } \\
\text { specimens }\end{array}$} & \multirow{2}{*}{$\begin{array}{c}\text { Total } \\
\text { number of } \\
\text { fish, } \\
\text { specimens }\end{array}$} \\
\hline & & $\begin{array}{l}\text { Cypri- } \\
\text { nidae }\end{array}$ & Percidae & $\begin{array}{l}\text { Coregonidae } \\
\text {-Esocidae }\end{array}$ & $\begin{array}{l}\text { Uniden- } \\
\text { tified }\end{array}$ & \\
\hline \multirow{2}{*}{$\begin{array}{l}\text { Vortex } \\
\text { zone (I) }\end{array}$} & $9.2-37.90$ & 72-499 & 30-169 & 7-39 & 5-33 & $114-740$ \\
\hline & 18.32 & 208 & 73 & 15 & 13 & 309 \\
\hline \multirow{2}{*}{$\begin{array}{l}\text { Out of the } \\
\text { vortex zone } \\
\text { (II) }\end{array}$} & $\underline{3.80-40.90}$ & $\underline{6-145}$ & $4-57$ & 2-14 & $\underline{1-12}$ & $21-226$ \\
\hline & 16.34 & 84 & 28 & 7 & 5 & 125 \\
\hline $\begin{array}{l}\text { Excess (I/II), } \\
\text { times }\end{array}$ & 1.12 & 2.48 & 2.61 & 2.14 & 2.60 & 2.47 \\
\hline
\end{tabular}

Note: * numerator shows minimum-maximum values, denominator-average.

During the analysis of the average number of fish recorded at one monitoring in different parts of the stream pocket, there was found a significant excess of this parameter for all taxonomic groups in the zones of vortices in relation to the zone of water area pocket, where the vortices were not recorded, equaling 2.48 times for Cyprinidae, 2.61 for Percidae, 2.14 for Coregonidae, and 2.60 for unidentified, even despite comparable parameters of bathymetric characteristics of different parts of the water body. As a result of statistical analysis, there was determined a reliable difference $(\mathrm{P}<0.05)$ by the parameter of number of fish for all recorded groups of fish in the zone of vortices and beyond the vortices.

Massive concentrations of fish in the zone of recorded vortices were determined visually before obtaining digital parameters in the process of analysis of the conducted hydroacoustic sounding (Fig. 2).

During the development the charts of horizontal distribution of fish for each taxonomic group, there were observed certain zones of the largest concentrations and different areas of diffusive distribution in the water area of the studied stretch of river (Fig. 3).

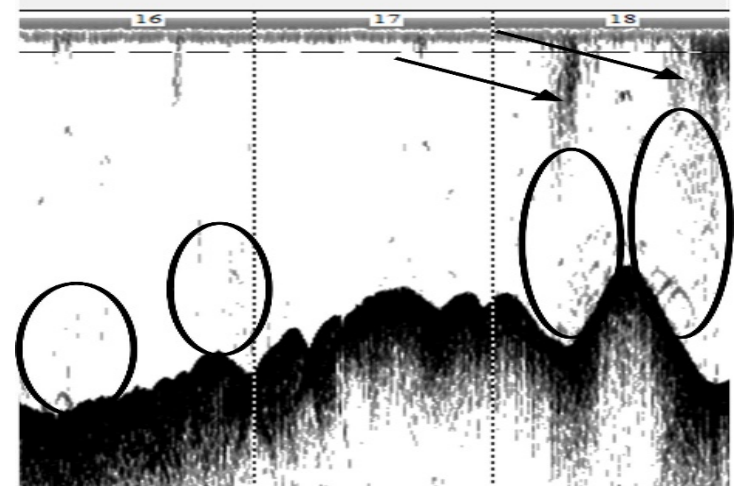

Fig. 2. Echogram (PanCor) of fish concentration in the zone of vortices (on the right) and out of the vortices (on the left) in the water area of the stream bed: the pointers indicate vortices, ovals - concentrations of fish

Analysis of distribution of the largest concentrations of fish demonstrated that the highest number of fish in the water area of the stream pocket was in the deepest part and directly in front of it, here were also recorded the most intense whirlpools (vortices) which form hydrodynamic non-uniformity of the environment (Fig. 3). The comparison of data by records of zones of "clouds of effervescence" and vortices demonstrates their significant coincidence with the zones of increased concentrations of fish of different families (Fig. 1, 3).

Size-taxonomic structure of the fish population. As a result of analysis of the size structure of the fish population in the water area of the riverbed depression out of the recorded vortex zone and within the vortex zone, it was determined that by number, among the cyprinids, 
3the dominant were the groups of body sizes $<15 \mathrm{~cm}(<5,5-10,10-15 \mathrm{~cm})$, their share equaled $91.2 \%$ and $93.3 \%(7.3,65.7,18.3 \%$ and 10.1 , $68.5,14.7 \%$ respectively) of the total number of recorded cyprinids in the corresponding parts of the water area of the riverbed depression (Fig. 4a). The shares of the size groups were 15-20, 20-25, 25-30, $30-35$ and $>35 \mathrm{~cm}-$ to $2 \%$.
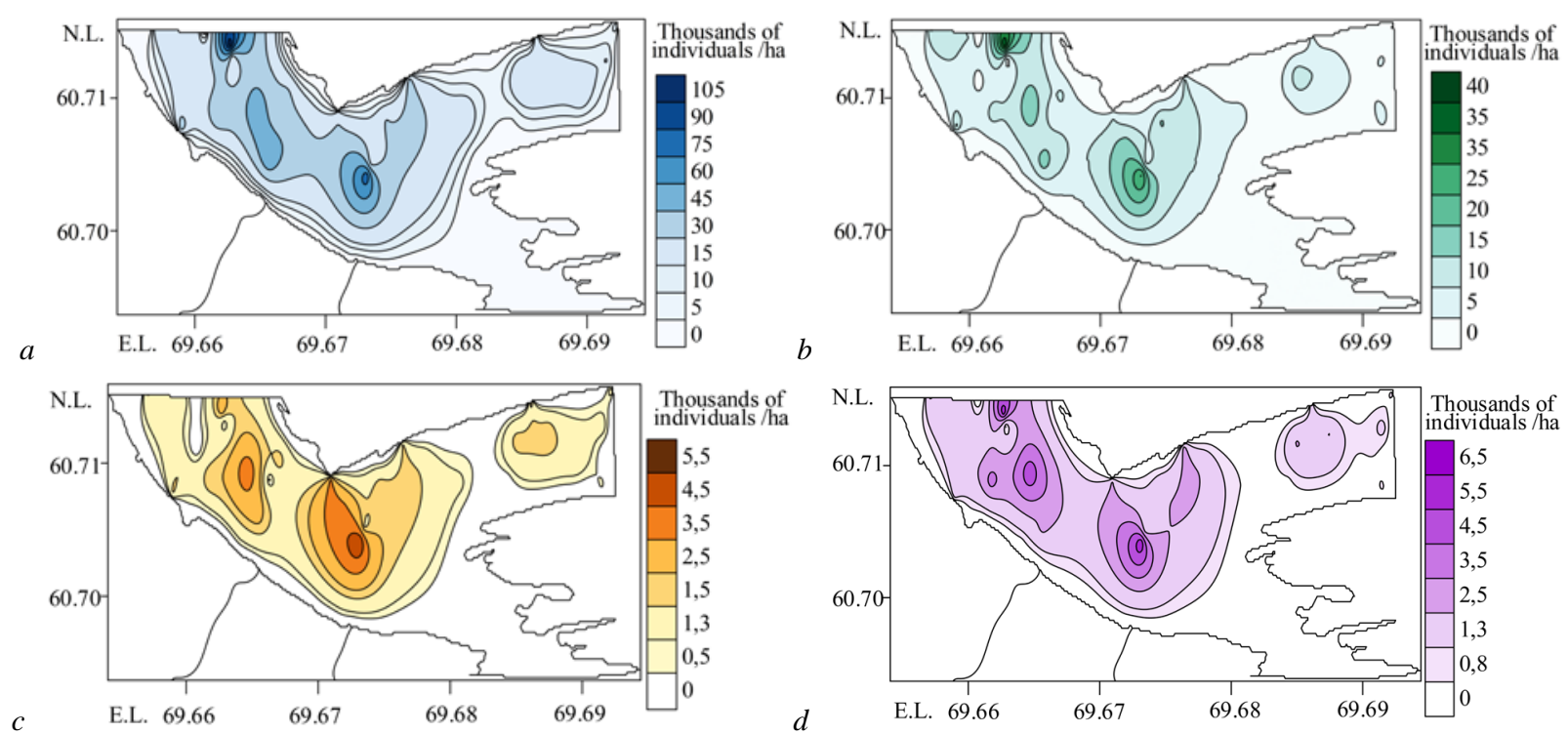

Fig. 3. Distribution of fish (thousands of individuals/ha) in the water area of the Kondinskaya riverbed depression: $a$ - Cyprinidae, $b$ - Percidae, $c$ - Coregonidae - Esocidae, $d$ - unidentified
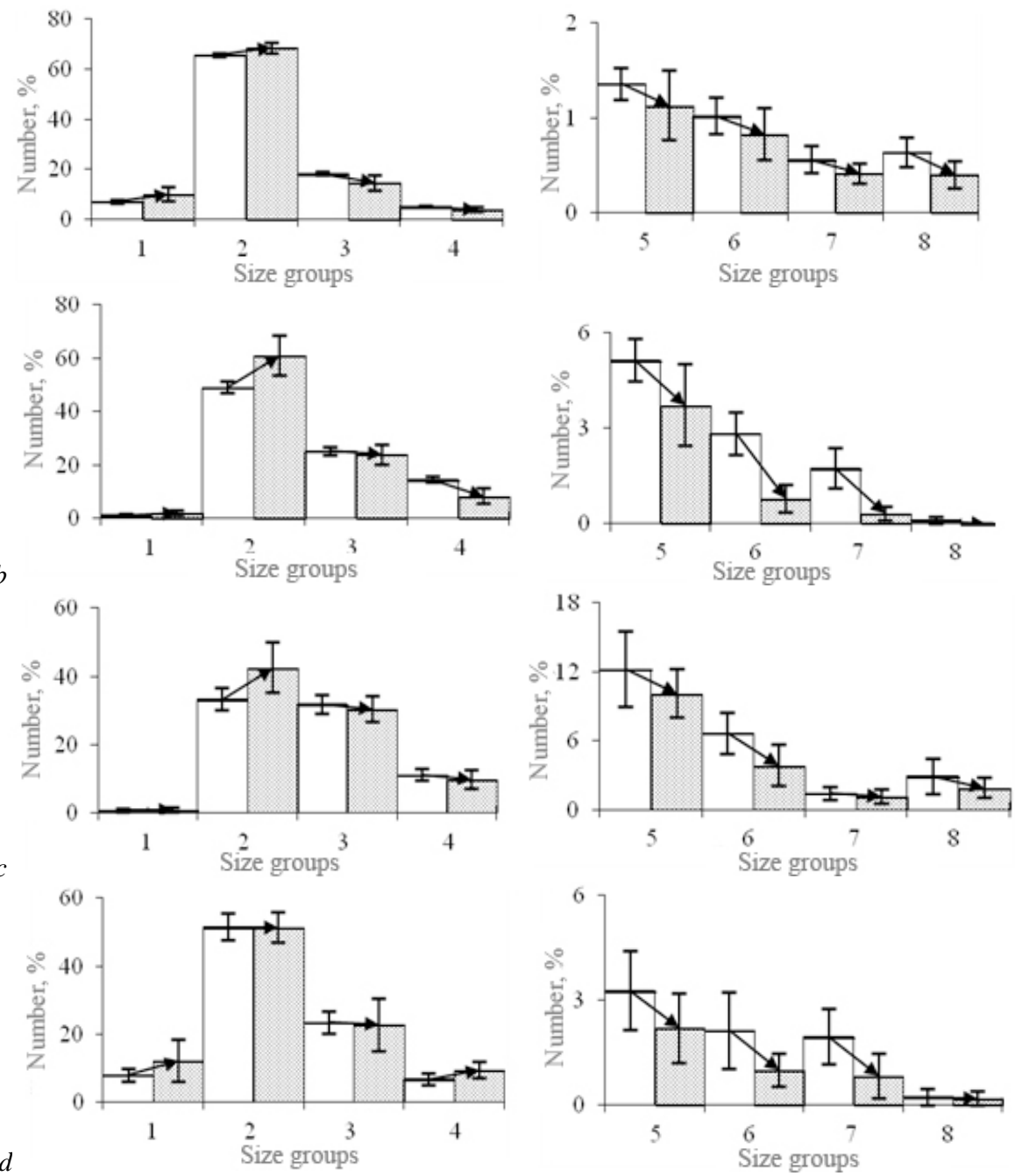

Fig. 4. Average values $(\mathrm{x} \pm \mathrm{m})$ of percent ratios of size groups of fish out of the vortex zone (not shaded) and in the vortex zone (shaded) of the Kondinskaya riverbed depression, the pointer indicates the orientation of the trend: $a$-Cyprinidae, $b$-Percidae, $c$-Coregonidae - Esocidae, $d$ - unidentified; size groups: $1-<5 \mathrm{~cm}, 2-5-10 \mathrm{~cm}, 3-10-15 \mathrm{~cm}, 4-15-20 \mathrm{~cm}, 5-20-25 \mathrm{~cm}, 6-25-30 \mathrm{~cm}, 7-30-35 \mathrm{~cm}, 8->35 \mathrm{~cm}$ 
The species structure of Cyprinidae fish population in the riverbed depression water area is represented in decreasing order: ide, roach, silver crucian, bream, dace and at the lowest level - gold crucian.

The main group of Percidae fish is represented by the size groups 5-10, 10-15, 15-20, 20-25 cm - 46.9, 25.3, 14.5, 5.1\% and 60.9, 23.9, 8.3, 3.7\% respectively (Fig. $4 b$ ). The largest differences in the quantitative and percentage ratio respectively outside the zone of vortices recording and within the vortex zone were observed for the size groups 5-10, 15-20, 20-25, 25-30, 30-35 cm. According to the control catch, the dominant species of this group were represented by zander and perch, and by ruffe at the lowest level.

The group of Coregonidae-Esocidae in the zone of vortices and in the rest of the water area of the stream pocket according to the data of the hydroacoustic sounding is represented mostly by individuals with body sizes of $-10,10-15,15-20,20-25,25-30 \mathrm{~cm}$. Their shares equaled $33.3,31.8,11.1,12.2,6.7 \%$ and $42.5,30.2,9.7,10.1,3.8 \%$ of the total number of fish of the recorded group out of the vortex zone and within it respectively. Significant differences in distribution in different zones of the water area were determined for most size groups, except individuals with body length $<5,10-15$ and $15-20 \mathrm{~cm}$. Among the representatives of this group in the period of the study, nelma dominated.

The main concentrations of unidentified fish (Acipenseridae, Lotidae) outside the vortex zone and within it were the individuals of the size groups $<5,5-10,10-15,15-20,20-25 \mathrm{~cm}$. The shares of their groups equaled 7.9, 51.5, 23.4, 6.7, 3.3\% and 12.2, 51.5, 22.8, 9.4, 2.2\%. Significant differences in distribution of this group of fish in the studied parts of the water area were determined for individuals with body sizes 5, 20-25, 25-30, 30-35 cm. According to the control catch, this group of fish in this period was represented by sterlet, Siberian sturgeon, and burbot was the rarest in the catch made in that period.

Thus, the percentage ratios of the groups of recorded fish both in the zone of vortices and out of the zone are close, but have particular differences, the pattem of which is seen in all of the fish groups. The shares of individuals with body sizes to $10 \mathrm{~cm}$ (the young) dominate in the part of the stream pocket where the vortices were recorded and the largest individuals (>10 cm) - out of the zones of vortices (Fig. 4).

\section{Discussion}

In the water area of the stretch site of the river, fish of different taxonomic groups and sizes concentrate. The dominant are Cyprinidae, the other most abundant species were the representatives of Percidae, Coregonidae, Acipenseridae, Lotidae, and Esocidae. Despite the high number of predators, non-predatory fish form large concentrations in this water area. It has been determined (Jacobsen et al., 2004; Snickars et al., 2004) that water turbidity offers some sort of shelter and protection from predators for Cyprinidae and young Percidae fish. This physical parameter of the media allows them to settle in new parts of the water area, moving out from the zones of aquatic plants. At the same time, the indicators of their natural death rate are comparable with those of the representatives of the corresponding families which live in the littoral vegetation of the water bodies with clean transparent water, using the plants as shelter.

Specific physical parameters of the water media of the studied part of the river, such as turbidity, can help non-predatory fish: detecting them becomes harder for the predatory species (Ranåker et al., 2012; Figueiredo et al., 2016), therefore the latter change their diet (Davis \& Pusey, 2010), at the same time the number of attacks decreases (VanLandeghem et al., 2011; Jönsson et al., 2012), the distance of detection and the success of attacks on the victims decreases (Hazelton \& Grossman, 2009), intensity of feeding decreases (Salonen \& Engström-Öst, 2010), for example, it was found (Jepsen, 2001) that pike in a water body with increased turbidity become less active and occupy a smaller water area, but retain their dynamic of daily activity. At the same time (Skov \& Koed, 2004), increased turbidity significantly decreases cannibalism among the predatory species of fish.

According to research data (Ljunggren et al., 2007), it was determined that within a family, different species of fish with relatively different sensory physiology (perch, zander) react differently to increase in turbidity of the environment, but in this case, their feeding activity and growth decrease. The concentration of a large number of young (small) individuals of carps in the presence of a large number of predators in conditions of heightened turbidity is explained by the predators' short distance of prey detection, which was proved in experimental studies on pike and roach (Ranåker et al., 2012, Jönsson et al., 2012), and also of other species of fish (Figueiredo et al., 2016). According to the researchers (Ohata et al., 2011; Höjesjö et al., 2015), structural complication of the environment is advantageous first of all the young fish for in such conditions, the risk of being preyed on decreases. It should be mentioned that the behaviour of predatory fish species in turbid environments becomes more complicated (Andersen et al., 2008; Jacobsen et al., 2015), thus the worsening of the conditions of prey detection are compensated. An interesting fact was determined (Carton, 2005): if the young fish in the process of ontogenesis are in turbid water, then they become more adapted to feeding in such conditions when they are older.

An experimental study (Vanderpham et al., 2013) demonstrated that in turbulent conditions of the water media, the fish consumption by predatory fish decreases, even in conditions of their universal adaptivity to water bodies with different hydrodynamic characteristics. Apart from turbidity, the dynamic heterogeneity of water media of the studied water area also provides "shelter" for young non-predatory fish. In its turn, in the conditions of selecting microbiotopes for optimum somatic growth or heightened survivability, (Stoll et al., 2008) young cyprinids (Eurasian dace, bream) prefer the latter even in the condition of stressful hydrodynamic impact caused by disturbance and movement of water masses.

Another factor which leads to significant effect on the distribution of fish in the pocket of the water area is turbulence and flow velocity gradient caused by it in the vertical and horizontal aspects of the water column. It was demonstrated (Lundvall et al., 1999) that at higher indicator of the turbulence flow and its pulsation, concentrations (large and small shoals) become more dense. This study mostly focused on whirlpools (vortices) which were recorded visually and by hydroacoustic sounding, in the zone of which there was found excess in the number of fish of all taxonomic groups, recorded using the hydoacoustic method, more than two times the number detected in the open water area of the pocket (out of the vortex zone). According to the theoretical description of structure and functioning of vortices (Verin, 2017), which indicates the centrifugal force in its body and the zone of decreased pressure in its center, it seems that this pattern is partly or fully related to indrafting and temporary retention of the fish in its complex physical structures. Experiments in pure water (Pavlov, 1979) indicated that in circulation flows, most fish orientate by visual signals when contradictions occur between visual and seismic-sensory orientation. Acipenseridae are an exception - they always orientate against the current.

At the same time, it was observed (Pavlov, 1979) that in turbid water, the role of eyesight significantly decreases, sometimes down to disappearance, but the young of both Cyprinidae and Acipenseridae in experiments with circular flow concentrate in its central part. Fish with disorders of eyesight organs are able to orientate in a current with circular flows using horizontal canals of the inner ear (Pavlov, 1979), for example goldfish (Harden-Jones, 1968) orientate in vortices of diameters up to $20 \mathrm{~m}$ and the flow velocity around $50 \mathrm{~cm} / \mathrm{s}$. In our study, the fish recorded in the vortex zone belong to different ecological and age groups and therefore have different indicators of critical velocities and sensitivity to the flow (Pavlov, 1979; Garner, 1999; Knaepkens et al., 2006). In the conditions of experimental studies on the selection of an area by fish in flow velocity gradient conditions, it was determined (Pavlov, 1979; Garner, 1999) that pelagic fish (perch, crucian, roach, Eurasian dace, and others) turn from the main current to the zone of the current axis. Among demersal fish, a similar reaction was demonstrated by burbot, representatives of Acipenseridae usually demonstrate a clear rheoreaction and orientate in relation to the axis of the current - actively move against the current. For non-predatory fish (Pavlov, 1979), absence of rheo- 
reaction can take place after an attack or visual detection of a predator, or another alarm, i.e. is an element of protection behaviour. In its turn (Pavlov, 1979; Linnansaari et al., 2010), in the conditions of flow velocity gradient, grown young fish prefer zones with higher velocities, (Pavlov, 1979) young cyprinids show rheoreaction already at body length of 18-25 mm. Also, it was demonstrated earlier (Garner, 1999) that young cyprinids prefer currents characterized by high flow velocities. During the analysis of the size structure of the fish population, it was determined that individuals with body size up to 10 $\mathrm{cm}$ dominate in the zone where vortices are recorded, and larger individuals - out of the zone. In our study, this pattern is universal for all recorded groups of fish. The peculiarity of the differentiation of concentration places of the young and large individuals of older age groups of fish is an additional element of the strategy of defensive behaviour of the young in the system "predator - victim" for (Turesson et al., 2002) large predators try to maximize consumption of prey per time unit, actively choosing a small victim. Such behaviour of predatory species of fish is logical for the success of catching usually negatively correlates with the size of prey, as a result small victims are selected (Einfalt \& Wahl, 1997, Lundvall et al., 1999).

\section{Conclusion}

Inside a complex hydrodynamic environment of turbulent currents of the riverbed depression, a differentiation of localization of concentrations of fish of different ecological and taxonomic groups occurs, mostly by size and quantitative parameter in the zone of whirlpools (vortices) and out of it. The number of fish in the vortex zone is over two times higher than this parameter out of this zone. In the vortex zone, the dominant fish were those with body sizes of less than $10 \mathrm{~cm}$, in the rest of the water area, larger fish dominated. On the one hand, the division of fish population by quantitative and size parameter inside the vortex zone of the river area occurs as a result of selection of necessary habitat conditions, on the other hand it occurs as a result of temporary indrafting and retention of the fish in the vortex zone. The determined peculiarities of fish distribution substantiate the described elements of defensive behaviour, more broadly reveal the role of dynamic parameters of the water environment and survival strategy of young fish in the "predator - victim" system.

This article was prepared with the financial support of FASO Russia within the following topic of Fundamental Scientific Research "Assessment of the condition of the winter riverbed depression as an element of the strategy of preserving populations of Coregonidae and Acipenseridae of the Ob-Irtysh basin”, State Registration Number 116020510083

\section{References}

Altenritter, M. E., Wieten, A. C., Ruetz, C. R., \& Smith, K. M. (2013). Seasonal spatial distribution of juvenile lake sturgeon in Muskegon Lake, Michigan, USA. Ecology of Freshwater Fish, 22, 467-478.

Andersen, M., Jacobsen, L., Grønkjær, P., \& Skov, C. (2008). Turbidity increases behavioural diversity in northern pike, Esox lucius L., during early summer. Fisheries Management and Ecology, 15, 377-383.

Baryshnikov, N. B. (2007). Dinamika ruslovykh potokov [Dynamics of channel flows]. RGGMU, St. Petersburg (in Russian).

Blanckaert, K., Kleinhans, M. G., McLelland, S. J., Uijttewaal, W. S. J., Murphy, B. J., van de Kruijs, A., Parsons, D. R., \& Chen, Q. (2013). Flow separation at the inner (convex) and outer (concave) banks of constant-width and widening open-channel bends. Earth Surface Processes and Landforms, 38, 696-716.

Borisenko, E. S., Degtev, A. I., Mochek, A. D., \& Pavlov, D. S. (2006). Hydroacoustic characteristics of mass fishes of the Ob-Irtysh Basin are investigated. Journal of Ichthyology, 46(2), 227-234.

Carton, A. G. (2005). The impact of light intensity and algal-induced turbidity on first-feeding Seriola lalandi larvae. Aquaculture Researches, 36, 1588-1594.

Davis, A. M., \& Pusey, B. J. (2010). Trophic polymorphism and water clarity in Northern Australian Scortum (Pisces: Terapontidae). Ecology of Freshwater Fish, 19, 638-643.

Einfalt, L. M., \& Wahl, D. H. (1997). Prey selection by juvenile walleye as influenced by prey morphology and behavior. Canadian Journal of Fisheries and Aquatic Sciences, 54, 2618-2626.
Figueiredo, B. R. S., Mormul, R. P., Chapman, B. B., Lolis, L. A., Fiori, L. F., \& Benedito, E. (2016). Turbidity amplifies the non-lethal effects of predation and affects the foraging success of characid fish shoals. Freshwater Biology, 61, 293-300.

Garner, P. (1999). Swimming ability and differential use of velocity patches by 0+ cyprinids. Ecology of Freshwater Fish, 8, 55-58.

Hansen, A. G., \& Beauchamp, D. A. (2015). Latitudinal and photic effects on diel foraging and predation risk in freshwater pelagic ecosystems. Journal of Animal Ecology, 84, 532-544.

Harden-Jones, F. R. (1968). Fish migration. Edward Arnold (Publishers) Ltd., London.

Hazelton, P. D., \& Grossman, G. D. (2009). Turbidity, velocity and interspecific interactions affect foraging behaviour of rosyside dace (Clinostomus funduloides) and yellowfin shiners (Notropis lutippinis). Ecology of Freshwater Fish, 18, 427-436.

Höjesjö, J., Gunve, E., Bohlin, T., \& Johnsson, J. I. (2015). Addition of structural complexity - contrasting effect on juvenile brown trout in a natural stream. Ecology of Freshwater Fish, 24, 608-615.

Jacobsen, L., Berg, S., Baktoft, H., \& Skov, C. (2015). Behavioural strategy of large perch Perca fluviatilis varies between a mesotrophic and a hypereutrophic lake. Journal of Fish Biology, 86, 1016-1029.

Jacobsen, L., Berg, S., Jepsen, N., \& Skov, C. (2004). Does roach behaviour differ between shallow lakes of different environmental state? Journal of Fish Biology, 65, 135-147.

Jepsen, N., Beck, S., Skov, C., \& Koed, A. (2001). Behavior of pike (Esox lucius $\mathrm{L}$.) $>50 \mathrm{~cm}$ in a turbid reservoir and in a clearwater lake. Ecology of Freshwater Fish, 10, 26-34.

Jönsson, M., Ranåker, L., Anders-Nilsson, P., \& Brönmark, C. (2012). Preytype-dependent foraging of young-of-the-year fish in turbid and humic environments. Ecology of Freshwater Fish, 21, 461-468.

Knaepkens, G., Baekelandt, K., \& Eens, M. (2006). Fish pass effectiveness for bullhead (Cottus gobio), perch (Perca fluviatilis) and roach (Rutilus rutilus) in a regulated lowland river. Ecology of Freshwater Fish, 15, 20-29.

Linnansaari, T., Keskinen, A., Romakkaniemi, A., Erkinaro, J., \& Orell, P. (2010). Deep habitats are important for juvenile Atlantic salmon Salmo salar L. in large rivers. Ecology of Freshwater Fish, 19, 618-626.

Ljunggren, L., \& Sandström, A. (2007). Influence of visual conditions on foraging and growth of juvenile fishes with dissimilar sensory physiology. Journal of Fish Biology, 70, 1319-1334.

Lundvall, D., Svanbäck, R., Persson, L., \& Byström, P. (1999). Size-dependent predation in piscivores: Interactions between predator foraging and prey avoidance abilities. Canadian Journal of Fisheries and Aquatic Sciences, 56, 1285-1292.

Mochek, A. D., Borisenko, E. S., Budaev, S. V., \& Pavlov, D. S. (2015). Summer and autumn distribution of fish in lake Glubokoe. Journal of Ichthyology, 55(3), 355-362.

Muška, M., Tušer, M., Frouzová, J., Draštík, V., Čech, M., Jůza, T., Kratochvil, M., Mrkvička, T., Peterka, J., Prchalová, M., Ř́ha, M., Vašek, M., \& Kubečka, J. (2013). To migrate, or not to migrate: Partial diel horizontal migration of fish in a temperate freshwater reservoir. Hydrobiologia. 707, 17.

Nakayama, S., Doering-Arjes, P., Linzmaier, S., Briege, J., Klefoth, T., Pieterek, T., \& Arlinghaus, R. (2018). Fine-scale movement ecology of a freshwater top predator, Eurasian perch (Perca fluviatilis), in response to the abiotic environment over the course of a year. Ecology of Freshwater Fish, 1, 1-15.

Ohata, R., Masuda, R., \& Yamashita, Y. (2011). Ontogeny of antipredator performance in hatchery-reared Japanese anchovy Engraulis japonicus larvae exposed to visual or tactile predators in relation to turbidity. Journal of Fish Biology, 79, 2007-2018.

Ovsyanik, M. V. (2016). Obrazovanie vodovorota, smercha [Formation of a vortex and a tornado]. Evraziyskiy Soyuz Uchenykh, 28, 78-84 (in Russian).

Pavlov, D. S. (1979). Biologicheskie osnovy upravleniya povedeniem ryb v potoke vody [The biological basis of the behavior of fish in the control of water flow]. Nauka, Moscow (in Russian).

Ranåker, L., Jönsson, M., Nilsson, P. A., \& Brönmark, C. (2012). Effects of brown and turbid water on piscivore-prey fish interactions along a visibility gradient. Freshwater Biology, 57, 1761-1768.

Salonen, M., \& Engström-Öst, J. (2010). Prey capture of pike Esox lucius larvae in turbid water. Journal of Fish Biology, 76, 2591-2596.

Skov, C., \& Koed, A., (2004). Habitat use of 0+ year pike in experimental ponds in relation to cannibalism, zooplankton, water transparency and habitat complexity. Journal of Fish Biology, 64, 448-459.

Snickars, M., Sandström, A., \& Mattila, J. (2004). Antipredator behaviour of 0+ year Perca fluviatilis: Effect of vegetation density and turbidity. Journal of Fish Biology, 65, 1604-1613.

Stoll, S., Fischer, P., Klahold, P., Scheifhacken, N., Hofmann, H., \& Rothhaupt, K.-O. (2008). Effects of water depth and hydrodynamics on the growth and distribution of juvenile cyprinids in the littoral zone of a large pre-alpine lake. Journal of Fish Biology, 72, 1001-1022. 
Turesson, H., Persson, A., \& Brönmark, C. (2002). Prey size selection in piscivorous pikeperch (Stizostedion lucioperca) includes active prey choice. Ecology of Freshwater Fish, 11, 223-233.

Vanderpham, J. P., Nakagawa, S., \& Closs, G. P. (2013). Feeding ability of a fluvial habitat-specialist and habitat-generalist fish in turbulent and still conditions. Ecology of Freshwater Fish, 22, 596-606.

VanLandeghem, M. M., Carey, M. P., \& Wahl, D. H. (2011). Turbidity-induced changes in emergent effects of multiple predators with different foraging strategies. Ecology of Freshwater Fish, 20, 279-286.
Velikanov, M. A. (1958). Ruslovoy protsess: Osnovy teorii [Channel process: The basics of theory]. Gosudarstvennoe Izdatel'stvo Fiziko-Matematicheskoy Literatury, Moscow (in Russian).

Vermeulen, B., Hoitink, A. J. F., van Berkum, S. W., \& Hidayat (2014). Sharp bends associated with deep scours in a tropical river: The river Mahakam (East Kalimantan, Indonesia). Journal of Geophysical Research: Earth Surface, 119, 1441-1454.

Yudanov, K. I., Kalikhman, I. L., \& Tesler, V. D. (1984). Rukovodstvo po provedeniyu gidroakusticheskikh s'emok [Guidelines for hydroacoustic surveys]. VNIRO, Moscow (in Russian). 